\title{
Sentinel-1 uydusu ile deprem kaynaklı yüzey çökme analizi: Sivrice-Doğanyol-Pütürge örneği
}

\author{
Earthquake induced surface subsidence analysis with Sentinel-1 satellite: Sivrice- \\ Doğanyol-Pütürge
}

\author{
Asena KARSLIOĞLU ${ }^{1, a}$, Mehmet Hanifi ALKAYIŞ*2,b, Mehmet İnanç ONUR ${ }^{1, c}$ \\ ${ }^{I}$ Eskişehir Teknik Üniversitesi, Mühendislik Fakültesi, İnşaat Mühendisliği Bölümü, 26555, Eskişehir \\ ${ }^{2}$ Süleyman Demirel Üniversitesi, Mühendislik Fakültesi, İnşaat Mühendisliği Bölümü, 32260, Isparta
}

• Geliş tarihi / Received: 15.01.2021 • Düzeltilerek geliş tarihi / Received in revised form: 08.03.2021 • Kabul tarihi / Accepted: 13.03 .2021

\begin{abstract}
$\ddot{O} \mathbf{z}$
Depremler, önlem alınmadığı takdirde büyük can ve mal kayıplarına neden olan doğal afetler arasındadır. Türkiye'de fay hareketlerine bağlı olarak geçmişten günümüze yer sarsıntıları yaşanmaktadır. Depremler sırasında oluşan titreşimler geçtikleri ortamlarda çeşitli şekil değiştirme ve deformasyonlara neden olmaktadır. Zeminlerde oluşan deformasyonlar ise etkileşim içerisinde olduğu yapıların stabilitesinin bozulmasına neden olabilmektedir. Bu çalışmada 2020 yılında yer sarsıntıları yaşanan Sivrice/Elazı̆̆ başta olmak üzere, Sivrice (Elazığ)-Doğanyol (Malatya)-Pütürge (Malatya) ilçelerini kapsayan alanda deprem kaynaklı yüzey çökme analizi yapılmıştır. 24 Ocak 2020 Cuma günü saat 20.55'de Elazığ ili Sivrice ilçesinde $\mathrm{Mw}=6.8$ büyüklüğ̈̈nde bir deprem meydana gelmiştir. Sentinel-1 verileri kullanılarak 14 Haziran 2019 ile 8 Haziran 2020 tarihleri arasındaki çeşitli depremlerle ilişkili yüzey çökmesi SNAP yazılımında belirlenmiştir. Çalışma alanında hesaplanan dikey yer değiştirmenin $-19 \mathrm{~cm}$ 'den (Doğanyol ve Pütürge kuzeydoğusunda) $32 \mathrm{~cm}$ 'ye kadar (Doğanyol ve Pütürge kuzeyi ile Sivrice güneybatısında) değiştiği belirlenmiş̧tir. Dikey yer değiştirme değerleri jeolojik birimler ile karşılaştıııldığında; yükselme alanları çalışma alanının kuzey-batı kısmındaki Paleojenik birimde tespit edilmiştir. Çalışma alanının güney kısmında yer alan Paleozoik ve prekambriyen metamorfik kayaçların bulunduğu jeolojik birimde ise çökme alanları gözlemlenmiştir. Meydana gelen depremlerle ilişkili yüzey çökme dağılımının belirlenmesi, gelecekte olası büyük deformasyon alanlarının tahminine yardımcı olacağı ve önlemler geliştirilebileceğini ortaya koymuştur.
\end{abstract}

Anahtar kelimeler: Deprem, Elazı̆̆, SAR, Sentinel-1, Yüzey çökmesi

\begin{abstract}
Earthquakes are among the natural disasters that cause great loss of life and property when no precautions are taken. Depending on the fault movement in Turkey, there are earthquakes from past to present. Vibrations that occur during earthquakes cause various deformations in the medium they pass through. The deformations that occur in the soils can cause the stability loss of the structures. In this study, earthquake-induced surface subsidence analysis was carried out in the area covering Sivrice/Elazığ, Sivrice (Elazı̆̆) - Doğanyol (Malatya) -Pütürge (Malatya) districts, where earthquakes were experienced in 2020. On Friday, January 24, 2020 at 20.55, an earthquake of $M w=6.8$ occurred in Sivrice district of Elazig province. Using Sentinel-1 data, surface subsidence associated with various earthquakes between June 14, 2019 and June 8, 2020 was determined in the SNAP software. It is determined that the calculated vertical displacement in the study area varies from $-19 \mathrm{~cm}$ (northeast of Doğanyol and Pütürge) to $32 \mathrm{~cm}$ (north of Doğanyol and Pütürge and southwest of Sivrice). When vertical displacement values are compared with geological units; heave areas are observed in the Paleogenic unit in the north-west part of the study area. Subsidence areas are observed in the geological unit where Paleozoic and precambrian metamorphic rocks located in the southern part of the study area. Determining the surface subsidence distribution associated with the earthquakes revealed that it will help the prediction of possible large deformation areas and precautions can be developed.
\end{abstract}

Keywords: Earthquake, Elazı̆̆, SAR, Sentinel-1, Surface subsidence

\footnotetext{
*b Mehmet Hanifi ALKAYIŞ; mehmethanifialkayis@gmail.com, Tel: (0532) 76460 02, orcid.org/ 0000-0003-0177-043X

${ }^{\mathrm{a}}$ orcid.org/ 0000-0001-5178-4069 $\quad{ }^{\mathrm{c}}$ orcid.org/ 0000-0002-2421-4471
} 


\section{Giriş}

Zeminlerde deformasyonların meydana gelmesine sebep olan dinamik etkilerden en tesirlisi ve en yaygın görüleni deprem etkileridir. Depremler yerkabuğunun kırılması ile oluşan titreşimlerin geçtikleri ortamları sarsma olayı olarak adlandırılmaktadır. Deprem etkisi ile farklı zeminlerde farklı deformasyonlar meydana gelmektedir. Depremlerde görülen zemin deformasyonları ise; yüzey yırtılması, bölgesel çökme, yamaç hareketleri, hacimsel sıkışma, sıvılaşma, oturma ve tasıma gücü yenilmeleri, akma kaymaları, yanal yayılmalar, kum volkanları şeklinde sıralanmaktadır (Onur, 2007).

Türkiye; Kuzey Anadolu Fay Hatt1, Doğu Anadolu Fay Hattı ve Batı Anadolu Fay zonları içerisinde olmasindan dolayı tarihten bu yana depremlerin etkisi altındadır. Tektonik yapısı nedeniyle arazisinin büyük bir kısmını sismik tehlike altındadır. Bununla birlikte, Avrasya-Arap-Afrika levhası arasında yer alan Türkiye, her döneminde yıkıcı depremler ile karşılaşmıştır.

Türkiye'de ve yakın çevresinde sismik aktivite 1900'lerden beri aletsel olarak gözlenmektedir. T.C. İçişleri Bakanlığı Afet ve Acil Durum Yönetimi Başkanlığ 1 (AFAD) ile Boğaziçi Üniversitesi Kandilli Rasathanesi ve Deprem Araştırma Enstitüsü (KRDAE) Türkiye'deki iki ana sismik ağ operatörüdür (Kadirioğlu vd., 2018). Geçmiş deprem kayıtlarına göre 1939 Erzincan,1999 Gölcük ve Düzce, 2011 Van ve 2020 Elazı ̆ depremleri Türkiye'yi etkileyen yıkıcı depremlerin başında gelmektedir. 2020 y1lı OcakHaziran ayları arasında Sivrice-DoğanyolPütürge'yi etkileyen Pütürge Segmenti aktifleşmiştir. Şekil 1'de bu bölge için 2000 - 2020 y1llar1 ve 2019 - 2020 y1llar1 arasinda 4.0 'dan büyük depremler gösterilmektedir.

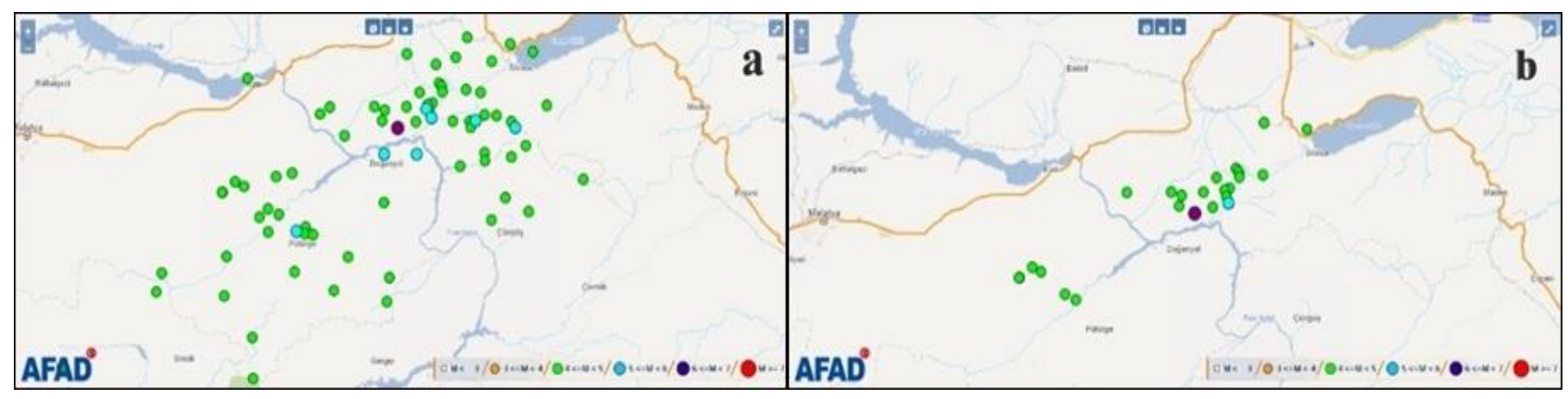

Şekil 1. Sivrice-Doğanyol-Pütürge'de görülen $M \geq 4$ depremler, (a) 2000 - 2020 y1lları arasında, (b) 2019 2020 y1lları arasinda (AFAD, 2020)

Elazığ ili Sivrice ilçesi Çevrimtaş köyü $800 \mathrm{~m}$ kuzeyinde 24 Ocak 2020 tarihinde meydana gelen büyüklüğü 6.8 , derinliği $8.05 \mathrm{~km}$ olan deprem, merkez üssüne $750 \mathrm{~km}$ mesafede 42 il merkezinde hissedilmiştir. Depremin merkez üssü ve yakın civarında Modifiye Marcelli Şiddet cetveline (MMI) göre maksimum şiddet IX (şiddetli) olarak hesaplanmış, 41 kişi yaşamını yitirmiş ve 1607 kişi yaralanmıştır. 547 bina tamamen yıkılmış, 6270 binada ağır hasar, 962 binada orta hasar ve 10273 binada az hasar meydana gelmiştir (AFAD, Şubat 2020).

2014 yılında uzaya gönderilen Sentinel-1A, Avrupa radar görüntüleme uydusudur. İnterferometrik Sentetik Açıklık Radarı (InSAR), gün ve hava koşullarında çalışma yetenekleri, geniş uzaysal kapsama alanı, ince uzaysal çözünürlüğü, yüksek ölçüm hassasiyeti ile öne çıkan gelişmiş bir jeodezik araçtır. Aynı alan üzerinde ancak farklı zamanlarda elde edilen iki SAR görüntüsü arasındaki faz farklarından yararlanarak InSAR,
Sayısal Yükseklik Modeli (SYM) oluşturmak ve zaman aralığ1 sirasında meydana gelen yer hareketini ölçmek için kullanılabilmektedir (Zebker ve Goldstein, 1986; Gabriel vd., 1989). Yer hareketini haritalamak için InSAR teknolojisi genellikle diferansiyel InSAR (DInSAR) olarak adlandırılır (Hu vd., 2014). Depremler, volkanik patlamalar ve heyelanlar sonucu meydana gelen yüzey çökmesini incelemek için uydular tarafından elde edilen Sentetik açıklıklı radar (SAR) görüntülerinin kullanımını içeren radar interferometrisi yaygın olarak kullanılmaktadır. SAR cihazı, C bandı radyo dalgaları yayarak yansımalarını yerden alır. SAR verilerini kullanarak, yüzey altı nükleer patlamalar nedeniyle yer değiştirme haritalaması da dâhil olmak üzere, dünyanın farklı yerlerindeki araştırmacılar tarafından diferansiyel DInSAR tekniği ile oldukça hassas yer değiştirme haritaları oluşturulmuştur (Amos, 2016). 
Solaro vd., (2016) 16 Eylül 2015'te Şili açıklarında meydana gelen $\mathrm{Mw}=8,3$ depremin sebep olduğu yüzey deformasyonunu Sentinel-1 verileriyle incelemiştir. DInSAR analizi sonucunda doğu-batı yer değiştirme haritası yaklaşı $210 \mathrm{~cm}$ 'lik batıya doğru yer değiştirmeyi belirtirken; dikey yer değiştirme haritası, kıyı boyunca yaklaşık $20 \mathrm{~cm}$ 'lik çökme ve yaklaşık $25 \mathrm{~cm}$ 'lik bir yükselme alanını göstermektedir. Xu vd., (2018) İran, Türkmenistan ve Afganistan'ın üçlü sınırının yakınında 2017 y1lında meydana gelen 6,1 büyüklüğündeki $(\mathrm{Mw})$ Sangsefid depremiyle ilişkili yüzey çökmesini belirlemek için Sentinel-1 SAR'1 kullanmıştır. Abdikan vd., (2019) 6 Şubat 2017 tarihinde Ayvacık-Çanakkale Mw $=5,3$ depremini DInSAR tekniği ile analiz etmiştir. Çalışma sonucunda, etkilenen alanlarda dikey yönde yaklaşı $9 \mathrm{~cm}$ yer değiştirme belirlenmiştir. Mevcut yapıların deprem ile etkileşimini öngörebilmek için kıtasal deformasyonun mekaniğini ve karmaşık tektonik deprem potansiyelini tahmin etmek gereklidir. Bu sebeple, sol-yanal atımlı Haiyuan fayının yakınında meydana gelen 2016 Menyuan (Qinghai) depremiyle ilişkili deformasyonu araştırmak için Sentinel-1 radar görüntülerini kullanmışlardır. Yükselen ve alçalan interferogramlardan, maksimum yer değiştirmeler $+58 \mathrm{~mm}$ ve $-68 \mathrm{~mm}$ olarak saptanmıştır (Wang vd., 2017).

2019'da Filipinler Mindanao'da art arda Mw> 6,4 olan dört güçlü deprem meydana gelmiştir. Araştırma raporlarına göre bu depremlere doğrultu atımlı kırılmalar neden olmuştur. Bu depremlerin zamansal ve mekânsal olarak ilişkisini anlamak için Sentinel-1 SAR verileri ile InSAR teknikleri kullanarak deprem kaynaklı yer değiştirme alanları incelenmiştir. InSAR deformasyon ölçümleri ile dört depremin farklı yer değiştirme modelleri ürettiği ortaya konulmuştur. Deprem serisinin, iki dikey sol yanal doğrultu atımlı fay ve iki sağ yanal doğrultu atımlı fay içeren birleşik bir fay yapısının yeniden harekete geçmesinden kaynaklandığ edilmiştir (Li vd., 2020). Ali vd., (2019) Pakistan'ın Pasni kıyısındaki $\mathrm{Mw}=6,3$ depreminin sebep olduğu arazi çökmesini incelemek için Sentinel-1 verilerini kullanmıştır. Araştırmada çalışma alanının çoğunlukla, deprem öncesinde aylık süre içerisinde $3 \mathrm{~cm}$ arazi yükselmesi gözlenirken deprem sonrası ise 12 günlük sürede toplamda $3 \mathrm{~cm}$ çökme gözlemlenmiştir. Çalışma alanının büyük bir bölümü ince kum, silt, ince tabakalı kumtaşı ve kalın tabakalı çamur taşı olduğundan, deprem sonrası hızlı bir çökme hareketi gözlemlenmiştir. İleride olabilecek sismik hareketlerin bölgenin altyapısına ve ekolojisine önemli zararlar verebileceği vurgulanmıştır.
Karslıoğlu vd., (2020) Türkiye'nin İç Anadolu Bölgesi'nde meydana gelen bölgesel çökmeleri DInSAR tekniği ile analiz etmiştir. Konya ili Karapınar ilçesinde bölgesel çökmenin 5-10 cm/yıl olduğu, bu değerin maksimum $16 \mathrm{~cm} / \mathrm{yll}$ 'a ulaşabileceği belirlenmiştir. Suresh ve Yarrakula (2020) 12 Kasım 2017'de İran/Irak sinırında 500 'ün üzerinde insanın yaşamını yitirdiği 7.3 büyüklüğündeki depremden kaynaklanan yüzey çökmesini DInSAR kullanılarak ölçülmesine odaklanmıştır. Thomas (2020) yapmış olduğu çalışmada ise 3 Nisan 2017 tarihindeki 5.2 büyüklüğündeki Stilfontein depremiyle ilişkili yer değiştirmeleri tespit etmek için Sentinel-1 SAR verilerine uygulanan DInSAR tekniğini kullanılarak radar interferometresinden elde edilen yüzey çökme haritalamasını kullanmıştır. Yaptığı diğer bir çalışmada Thomas (2020), Sentinel - 1 verileri ve SNAP kullanılarak 3 Nisan 2017'deki 6,5 büyüklüğündeki Botsvana depremiyle ilişkili yüzey deformasyonunun haritalanması için DInSAR analizi gerçekleştirmiştir. Hesaplanan dikey yer değiştirme $-12.2 \mathrm{~cm}$ ile $+13.6 \mathrm{~cm}$ arasında değişmektedir. Bayik (2021) 14 Haziran 2020 tarihinde Karlıova (Bingöl) 'de meydana gelen $\mathrm{Mw}=5.7$ depreminin neden olduğu yüzey deformasyonu, farklı geliş açılarına sahip Sentinel1 SLC görüntüleri ile belirlemiştir. InSAR tekniği $\mathrm{Mw}<6$ olan depremlere uygulanmadığından sonuçların sağlanması için çalışmada iki yükselen ve iki alçalan yörünge kullanılmıştır. Depremin yarattığı maksimum yatay yer değiştirme doğuda $13 \mathrm{~cm}$, batıda $15 \mathrm{~cm}$ olarak elde edilmiştir. Ayrıca düşey yönde fayın kuzey kesiminde $10 \mathrm{~cm}$ 'ye kadar yükselme ve fayın güney kesiminde $10 \mathrm{~cm}$ 'ye kadar çökme tespit edilmiştir. Diğer bir çalışmada doğu Kachch havzasını etkileyen aktif yüzey çökmesini, Envisat ve Sentinel-1 radar görüntülerini kullanarak DInSAR tekniği ile araştırılmaktır. ENVISAT-ASAR verileri kullanılarak elde edilen 2003-2005 y1lları için 0,2-0,3 cm, 2006-2009 yılları için 0,19-0,22 cm ve 2018-2020 Sentinel-1A verilerinin analizine göre ise $0,16-0,18 \mathrm{~cm}$ kümülatif bir yer değiştirme elde edilmiştir. Çalışma alanında daha zayıf yapılardan oluşan bölgelerin gelecekte büyük bir depremi tetikleyebileceği vurgulanmıştır (Lakhote vd., 2020).

Doğu Anadolu Fay (DAF) sistemi boyunca meydana gelen depremler, Türkiye'de görülen ve büyüklüğü 4.0 ve üzeri olan bütün depremlerin $\%$ 4.2'sini oluşturmaktadır. DAF üzerinde en son 1893 yılında Çelikhan-Gölbaşı segmentinde olan 7.3 ve 1905 y1lında Hazar-Sincik segmentinde 6.8 büyüklüğündeki hasar yapıcı depremler meydana 
gelmiştir. Uzun zamandır aktif olmayan DAF üzerinde, Elazığ'da meydana gelen 6.8' lik deprem sonrasında özellikle Sivrice-Malatya-Adıyaman yöresinde depremlerin görüleceği tahmin edilmektedir. Sivrice-Doğanyol-Pütürge bölgesi bu çalışma için araştırma alanı olarak seçilmiştir. Çalışma alanında, 24 Ocak 2020 ile 24 Şubat 2020 tarihleri arasındaki aylık veriler değerlendirildiğinde; ana şok dâhil olmak üzere toplamda 3080 adet deprem meydana geldiği ve bu artçılardan 26 tanesinin 4.0 ve üzeri büyüklükte olduğu belirlenmiştir. Risk teşkil eden bu bölgelere dikkat çekmek için Elazığ-Sivrice bölgesinde DInSAR tekniğini kullanılarak depremlerin oluşturduğu yüzey çökmeleri incelenmiştir. Çalı̧̧ma alanında birçok deprem görülmesinden dolayı hem 1 y1llik analiz hem de 6.8'lik depremi içine alan 1 aylık analiz gerçekleştirilmiştir.

\section{2. Çalışma alanı ve yöntem}

\section{1. Çalışma alanı}

Çalışmada Doğu Anadolu Fay Hattında bulunan Sivrice(Elazığ) - Doğanyol(Malatya) Pütürge(Malatya) yerleri için 14/06/2019 ile $08 / 06 / 2020$ ve $04 / 01 / 2020$ ile 04/03/2020 tarihlerine ait dört görüntü indirilmiştir. Görüntüler için $250 \mathrm{~km}$ tarama alanı ve $5 \mathrm{~m}$ x $20 \mathrm{~m}$ mekânsal çözünürlükle kaydedildiği İnterferometrik Geniş Alan modu (IW) SLC formatı ve VV polarize Cband verileri kullanılmıştır. Şekil 2'de gösterilen çalışma alanı 8192,80 km² dir.

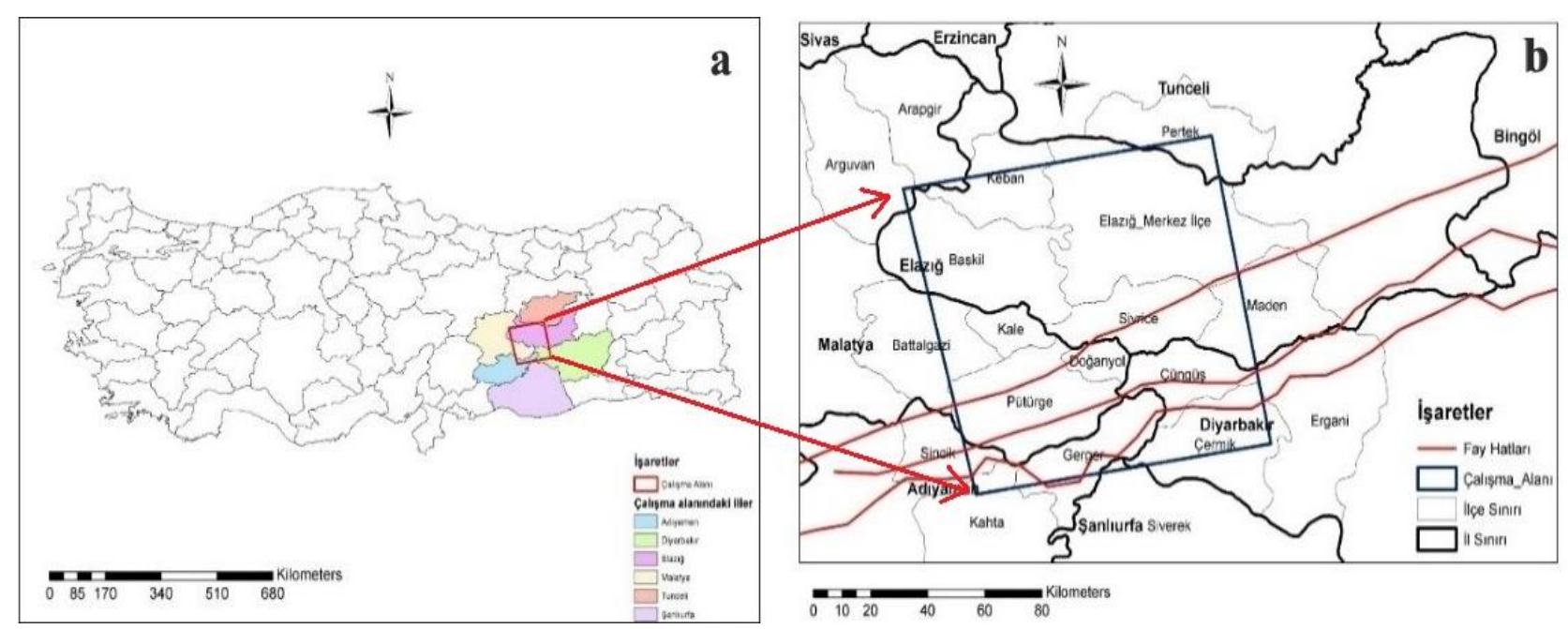

Şekil 2. Çalışma alanı

Jeolojik haritaları fay hatları gibi oluşumlar ile kaya birimleri arasındaki ilişkiyi gösteren haritalardır. Şekil 3'te çalışma alanının jeoloji haritas1 gösterilmektedir. $\mathrm{Bu}$ harita ArcGIS çevrimiçi veri tabanında bulunan Avrupa Jeoloji Haritasındaki verilerin kullanılması ile oluşturulmuştur. Çalışma alanı için revize edilerek kullanılmıştır.

Elazığ-Sivrice depremi, sismolojik verilere göre DAF zonunun orta kısmında bulunan Pütürge
Segmentinde meydana gelmiştir. Pütürge Segmenti boyunca, Paleozoyik-Alt Mesozoyik kayalar ve Mesozoyik-Senozoyik yaşlı ofiyolitik melanj bulunmaktadır (Hempton, 1985; Herece ve Akay, 1992; Yazgan, 1984). Elazı ğ ili Sivrice ilçesi ile Fırat Nehri arasında, Kuvaterner yaşlı çökeller yer almaktadır. Doğanyol batısından, Şiro Çayı vadisine ilerleyen fay, sol yönlü doğrultu atımlı aktif tektonik morfolojiyi göstermektedir (MTA, Şubat 2020). 


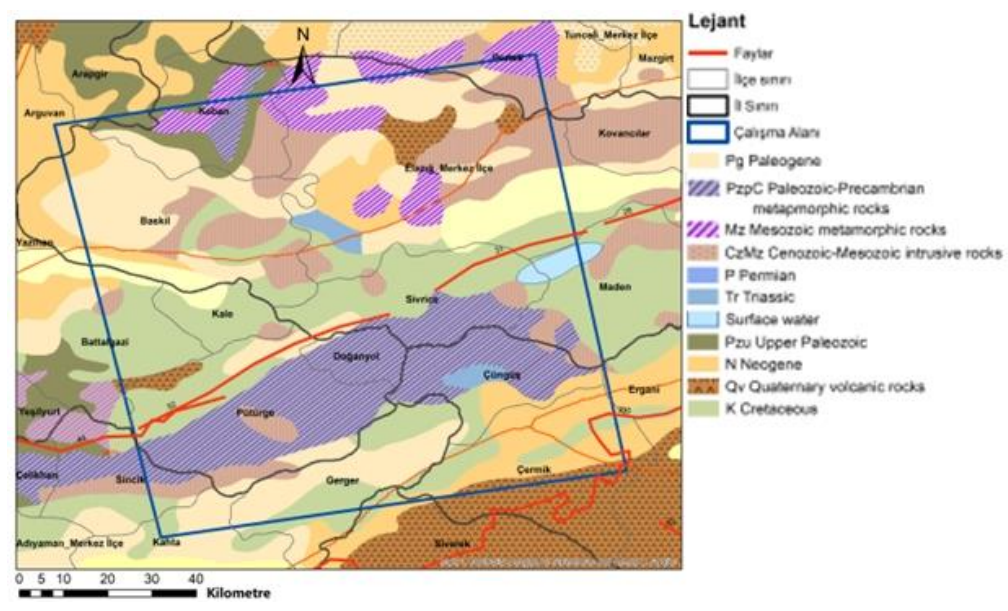

Şekil 3. Çalışma alanı jeoloji haritası

\subsection{Yöntem}

Sentinel-1 verilerine ücretsiz ve kolay erişim olmasından dolayı, veriler birçok uygulamada kullanılmaktadır. Sentinel-1, 4 özel mod şeklinde çalışmaktadır. Her mod için SAR Level-0, Level-1 Single Look Complex (SLC), Level-1 Ground Range Detected (GRD) ve Level-2 Ocean $(\mathrm{OCN})$ 'de veriler üretmek mümkün olmaktadır. Seviye-1 SLC ürünleri, uydudan gelen yörünge ve tutum verilerinden yararlanarak coğrafi referanslı ve sıfir doppler eğimli menzil geometrisinde sağlanan odaklanmış SAR verilerinden oluşur. Ürünler, tam aktarım sinyali bant genişliğini kullanan her boyutta tek bir görünüm içerir ve faz bilgisini koruyan karmaşık örneklerden oluşur. İnterferometrik Geniş Alan modu (IW) faal durum mod olması ile mevcut servis gereksinimlerinin çoğunu karşılar, uyuşmazlıkları önler ve görev planlamasını basitleştirir. Büyük bir tarama alan genişliğini $(250 \mathrm{~km})$ orta bir geometrik çözünürlükle $\left(\begin{array}{lllll}5 & \mathrm{~m} & \mathrm{x} & 20 & \mathrm{~m}\end{array}\right)$ birleştirilmesini sağlamakla birlikte arazi üzerinde kullanılabilmektedir (URL-1, 2020).

InSAR, iki SAR görüntüsü arasındaki faz farkına dayanarak dünya yüzeyindeki yer değiştirmeleri birkaç santimetre veya daha düşük bir hassasiyetle ölçmek için kullanılır. İki SAR görüntüsü bir depremden önce ve sonra elde edilirse, faz farkının bir kısm1, uydu görüş hattı yönündeki yüzey çökmelerinin tek boyutlu ölçüsüne karşıllk gelir. Ayrıca, bir depremin neden olduğu yüzey yer değiştirmelerinin uzaktan haritalanmasına imkân vermektedir. InSAR verileri kullanılarak başarıyla tespit edilen ve modellenen ilk deprem 28 Haziran 1992'de gerçekleşen ve büyüklüğü 7.3 olan Landers depremi olup (Massonnet vd., 1993) o zamandan beri jeodezik veriler kullanılarak araştırılan sismik olayların sayısı istikrarlı bir şekilde artmıştır. InSAR ile herhangi bir modellemeye gerek kalmadan interferogramda deprem çatlaklarının yerini görsel olarak belirlemek genellikle mümkündür (Weston vd., 2012).

DInSAR belirli bir zamanda iki görüntü arasındaki faz değişikliklerini gözlemlemek ve çökme/yükselme veya yanal deformasyonu izlemek için kullanılır. Topoğrafyadan bağımsız olması için, topografik faz bir referans SYM kullanılarak simüle edilir ve daha sonra interferogramdan çıkarılır. DInSAR, geniş mekânsal kapsama alanı ve sağladığı yüksek hassasiyet nedeniyle arazi sıkıntısını izlemek için etkili ve uygun maliyetli bir teknik olarak kabul edilebilir (Sowter vd., 2016). Radar bandları C band1, $\mathrm{L}$ band1, $\mathrm{X}$ bandı ve $\mathrm{K}$ bandidir. $\mathrm{Bu}$ sensörler, dalga boylarına göre farkl1 uygulamalarda kullanılmaktadır. Madencilik bölgelerindeki çökmeyi izlemek için C bandı ve L bandı veri setlerini karşılaştıran bir çalışma yapılmış ve sonuçlar $\mathrm{C}$ bandının daha hassas olduğunu kanıtlamıştır (Refice vd., 2003).

Çalışmanın amacı Haziran, 2019 ile Haziran, 2020 tarihleri arasındaki yıllık değişimi gözleyip, SAR verileri kullanılarak Sivrice-Doğanyol-Pütürge bölgesi Deprem kaynaklı yüzey çökme analizini yapmaktır. İnterferometrik analiz, SRTM 1 Second HGT kullanılarak gerçekleştirilmiştir. Kullanılan SRTM 1 Second HGT, Sentinel-1 verilerinin VV polarizasyon alt alanları ve $30 \mathrm{~m}$ çözünürlüğe sahiptir. DInSAR tekniği ve C-band verileri kullanılarak gerçekleştirilen çalışmada izlenen adımlar şeklinde Tablo 1'de gösterilmiştir. 
Tablo 1. İş-akış diyagramı
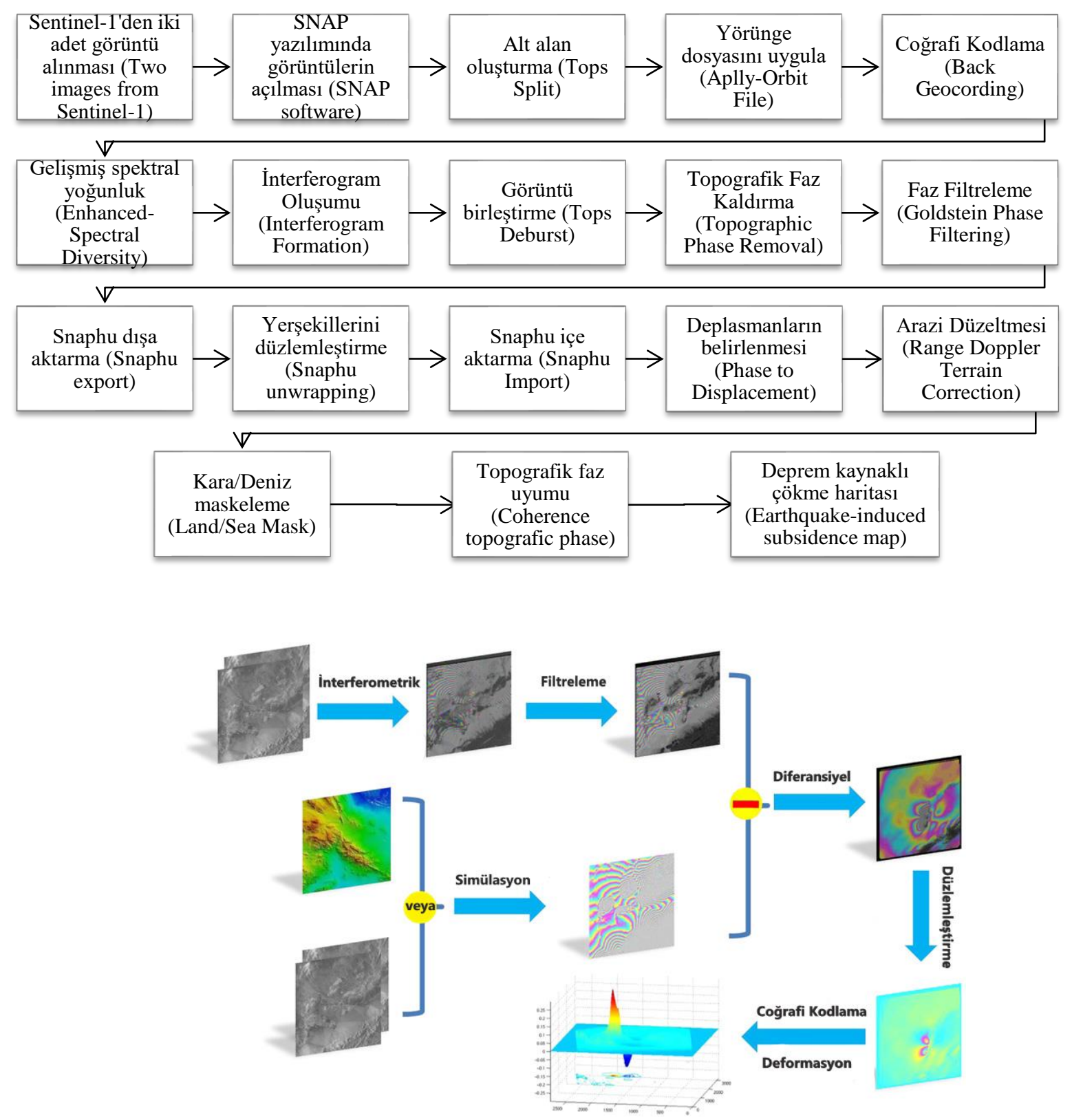

Şekil 4. D-InSAR'ın temel işlem akışı (Hu vd., 2014)

SNAP yazılımında bulunan iki geçişli DInSAR tekniği, 24 Ocak 2020 depremi öncesi ve sonras1 için elde edilen Sentinel-1 SAR (tek görünüm karmaşık veya SLC) verileri üzerinde yüzey çökmesinin yeri ve genliğini belirlemek için Şekil 4 'de verildiği gibi uygulanmıştır. Bu çalışmada yüzey çökme haritalaması için uygulanan diferansiyel interferometrik analiz ana adımları şu şekilde sıralanabilir: seçilen alt alanlar için iki Sentinel-1 SAR görüntüsünün birlikte kayd1, interferogram oluşumu, topografik faz kaldırma, faz filtreleme ve yer değiştirmenin hesaplanması.

İki farklı tarihte elde edilen aynı alan üzerindeki aynı geometriye sahip ve sensör modu IW olan iki adet SLC görüntüsü Şekil 5 'de görülebileceği gibi Sentinel-1'den indirilir ve Sentinel Uygulama Platform (SNAP) yazılımı kullanılarak düzeltilir. İki patlama arasındaki sınır bölgesini kaldırmak için Sentinel-1 TOPS menüsünden S-1 Deburst operatörü kullanılarak 3. adımdan elde edilen sonucun çapakları giderilir. Bir kümedeki tüm patlamaları tek bir görüntüde Şekil 6.b'deki gibi birleştirilir. Şekil 7.a'da görüldüğü üzere işlenen görüntü interferogramdan çıkarılır. Gürültüyü azaltmak için Faz Filtreleme yapılır. Statical-cost mode: DEFO, Initial Mode: MCF seçilerek yüzey çökmeleri belirlenir. Ardından su ve kara alanlarını ayırmak için Kara/Deniz maskeleme (Land-Sea Mask) operatörü SRTM 3 sec komutu kullanılarak 
çökmeler belirlenir. Faz interferogramından Şekil 7.b'deki gibi yüzey çökme haritası oluşturulur. Oluşan deprem kaynaklı yüzey çökme, GeoTIFF uzantı dosyası biçiminde dışa aktarılır. ArcGIS programında GeoTIFF dosyası ölçek, kuzey yönü ve işaretler eklenerek deprem kaynaklı yüzey çökme haritası şeklinde elde edilir.

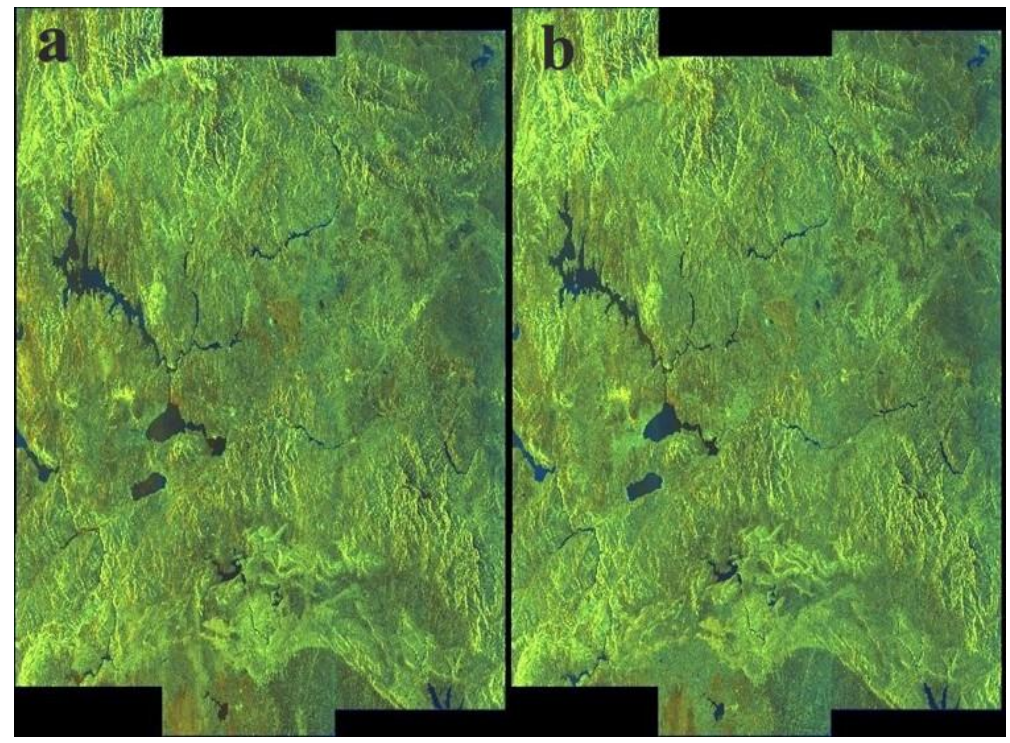

Şekil 5. (a) 14 Haziran 2019 Sentinel-1'den alınan görüntü (b) 8 Haziran 2020 Sentinel1'den alınan görüntü
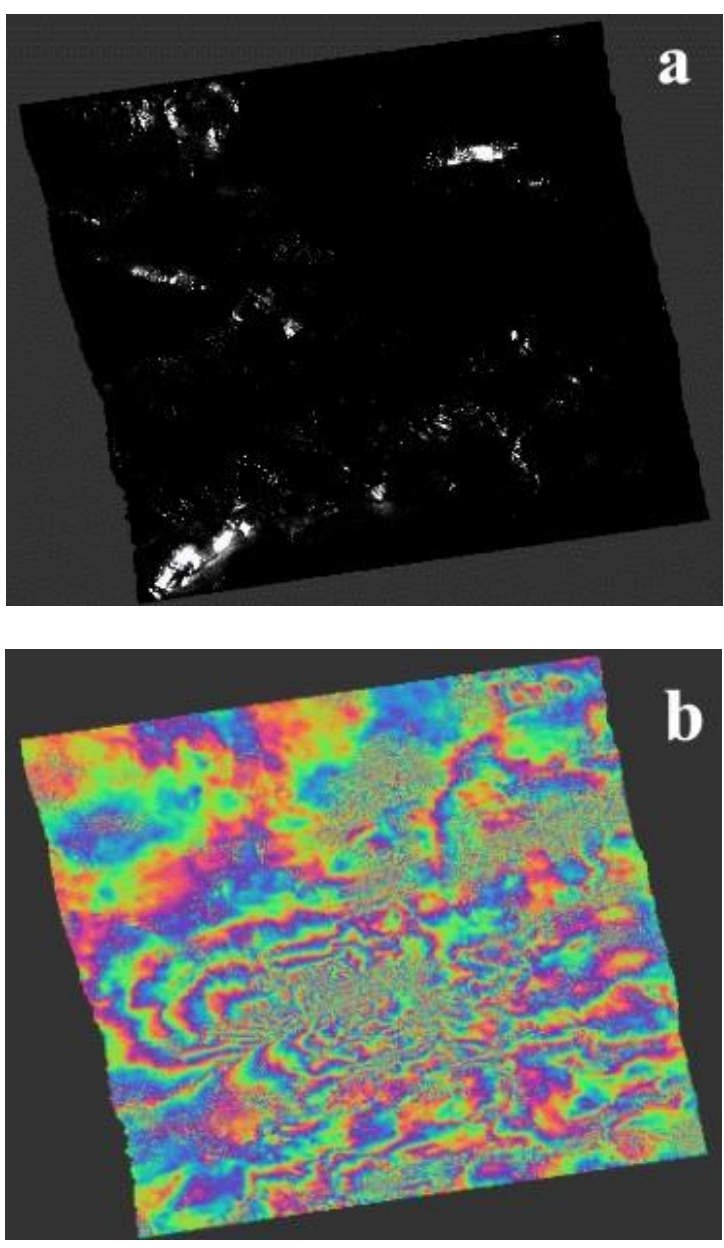

Şekil 6. (a) İnterferogram oluşumu (b) Görüntü birleştirme
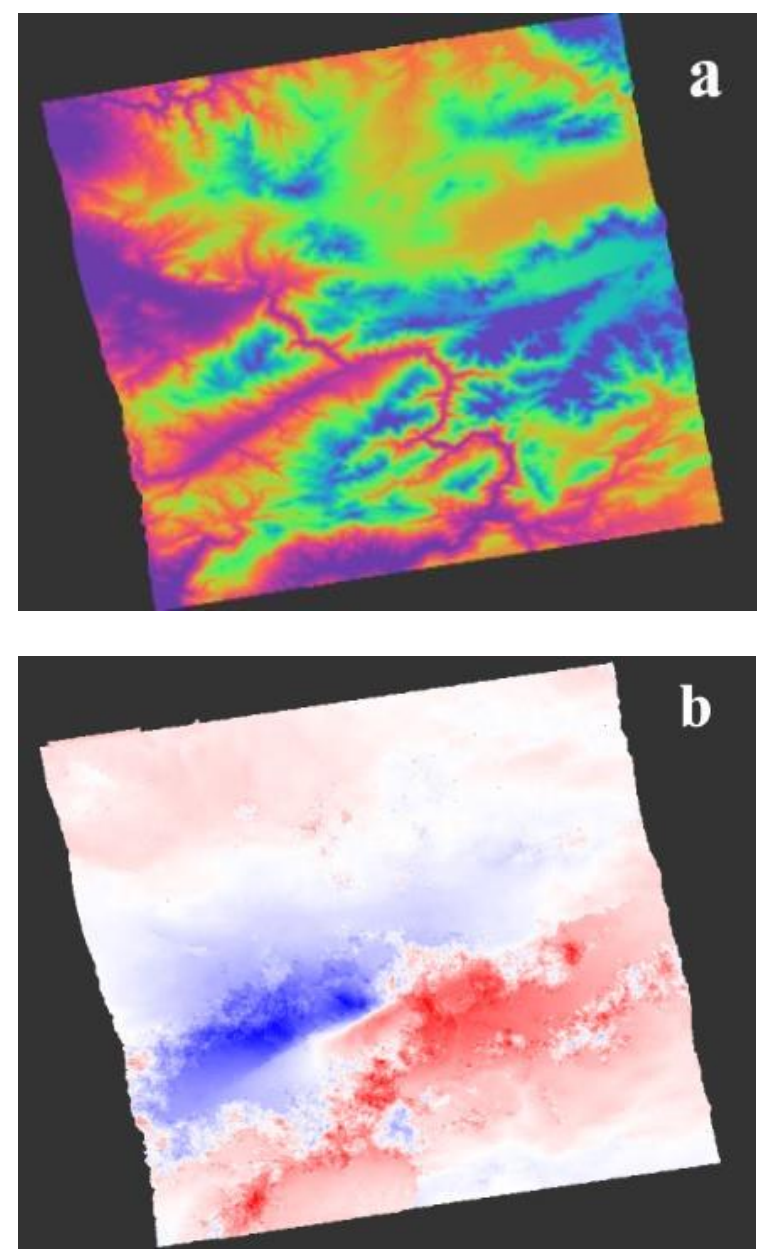

Şekil 7. (a) Topografik faz kaldırma (b) Yüzey çökme haritası 


\section{Bulgular ve tartışma}

Elazığ-Sivrice depreminin neden olduğu yüzey çökmesinin değerlendirilmesi Sentinel 1 veri setleri kullanılarak yapılmıştır. 24 Ocak 2020 tarihinde gerçekleşmiş 6.8 büyüklüğündeki depremi kapsayan 4 Ocak 2020 ile 4 Mart 2020 tarihleri arasında $+26 \mathrm{~cm}$ ile $-17 \mathrm{~cm}$ çökme değerleri, 14 Haziran 2019 ile 08 Haziran 2020 tarihleri arasının analizi sonucunda $+32 \mathrm{~cm}$ ile -19 cm çökme değerleri elde edilmiştir. Şekil 8.a'da çökme yoğunluklarının $+8 \mathrm{~cm}$ ile $-5 \mathrm{~cm}$ arasında, Şekil 8.b'de ise $+9 \mathrm{~cm}$ ile $-5 \mathrm{~cm}$ arasında olduğu görülmektedir. Sonuç olarak çökme değerlerinin çalışma alanının çoğunluğunda $+9 \mathrm{~cm}$ ile $-5 \mathrm{~cm}$ arasında olduğu ancak lokal olarak $19 \mathrm{~cm}$ çökme ile $32 \mathrm{~cm}$ yükselme noktalarının da mevcut olduğu tespit edilmiştir.
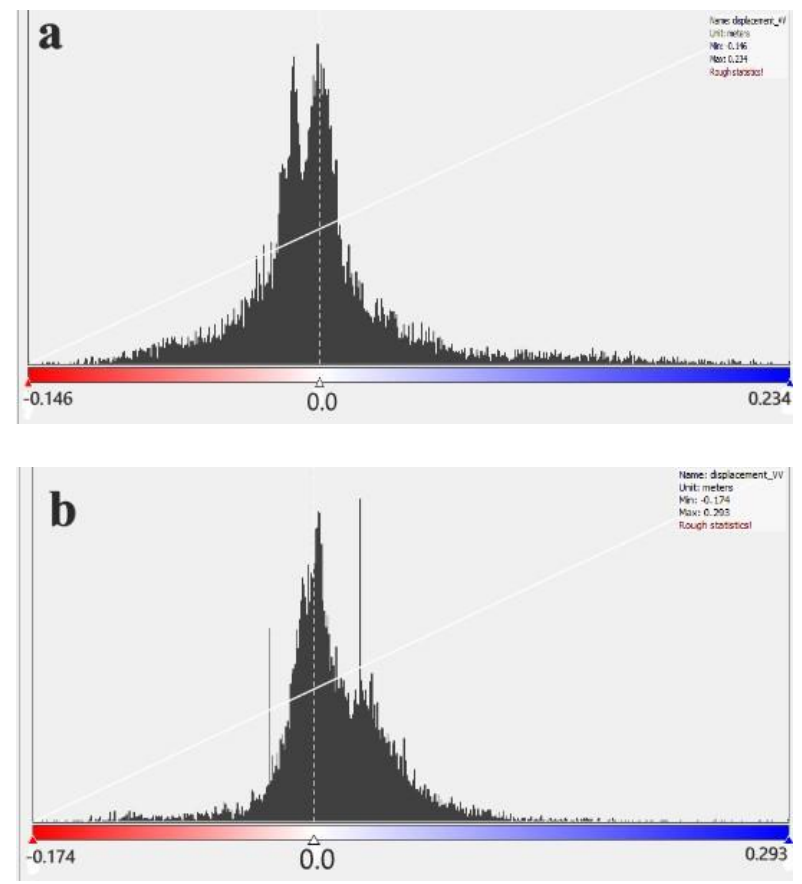

Şekil 8. (a) 4 Ocak 2020 ile 4 Mart 2020 tarihleri arasındaki ve (b) 14 Haziran 2019 ile 08 Haziran 2020 tarihleri arasındaki deprem kaynaklı yüzey çökme yoğunluğu

Bell vd., (2012) atmosferik koşullar ve uydu yörünge belirsizlikleri nedeniyle, 6'dan büyük depremlerin InSAR teknikleri kullanılarak yüzey çökme haritalaması gerektiğini ileri sürmüştür. Thomas (2020) yapmış olduğu çalışmada 5.2 büyüklüğ̈̈ndeki depremde $-1.8 \mathrm{~cm}$ ile $+4.5 \mathrm{~cm}$ çökme belirlemiş ve InSAR tekniğinin güvenilirliğini vurgulamıştır. Suresh ve Yarrakula (2020) 7.3 büyüklügünde depremin yüzey çökme analizine göre, maksimum $+85.1 \mathrm{~cm}$ ile $-18.3 \mathrm{~cm}$ çökmenin meydana geldiğini ve alanın yaklaşık $1500 \mathrm{~km}^{2}$ sinin ciddi şekilde etkilendiğini bulmuştur.

Analizlerde elde edilen toplam çökme değerinin genel olarak $\mathrm{Mw}=6.8$ depremi sonucunda oluştuğunun tespiti, literatür ile uyumlu olarak DInSAR tekniğinin $\mathrm{Mw}>6$ olan depremlerin yüzey çökme haritalaması için iyi bir yöntem olduğunu göstermektedir. Diğer yandan uydu görüntüleri ile saha verileri ilişkilendirildiğinde Şekil 9'da gösterilen Çevrimtaş köyü çevresindeki yüzey çökmeleri, analiz sonucunu destekler niteliktedir. Tatar vd., (2020) tarafindan yapilan saha çalışmalarının SAR verileriyle uyumlu olduğu görülmektedir.

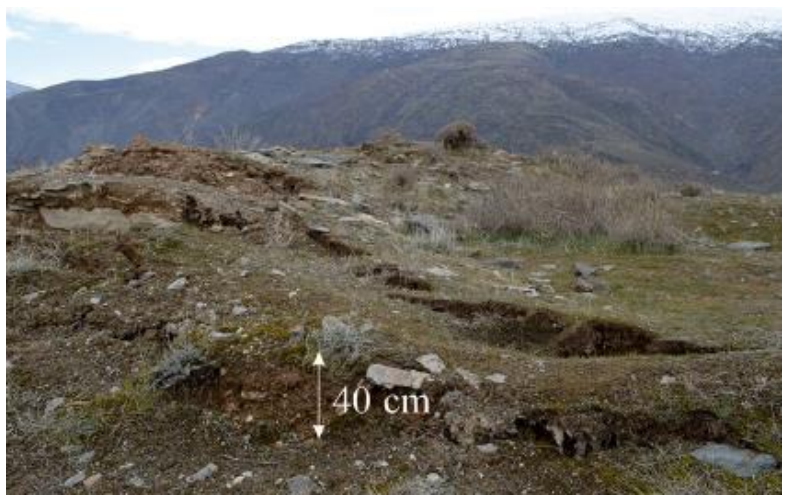

Şekil 9. Çevrimtaş köyü çevresindeki yüzey çatlaklarını gösteren alan görünümleri (Tatar vd., 2020)

Depremin oluştuğu fayın mekanizması AFAD raporuna göre sol yönlü doğrultu atımlı olduğu doğrulanmıştır (AFAD, 2020). Merkez üssünün konumu ve fay mekanizması DAF zonu'nun Pütürge segmenti boyunca yüzey çökmesi oluşumuna işaret etmektedir (Tatar vd., 2020). Fay hatlarının iki yakası boyunca pozitif ve negatif yer değiştirmeler görülmektedir. Yüzey çökmeleri incelendiğinde ise deprem merkez üslerine yakınlığın yanı sıra jeolojik birimlerin de rol oynadığı görülmektedir. 


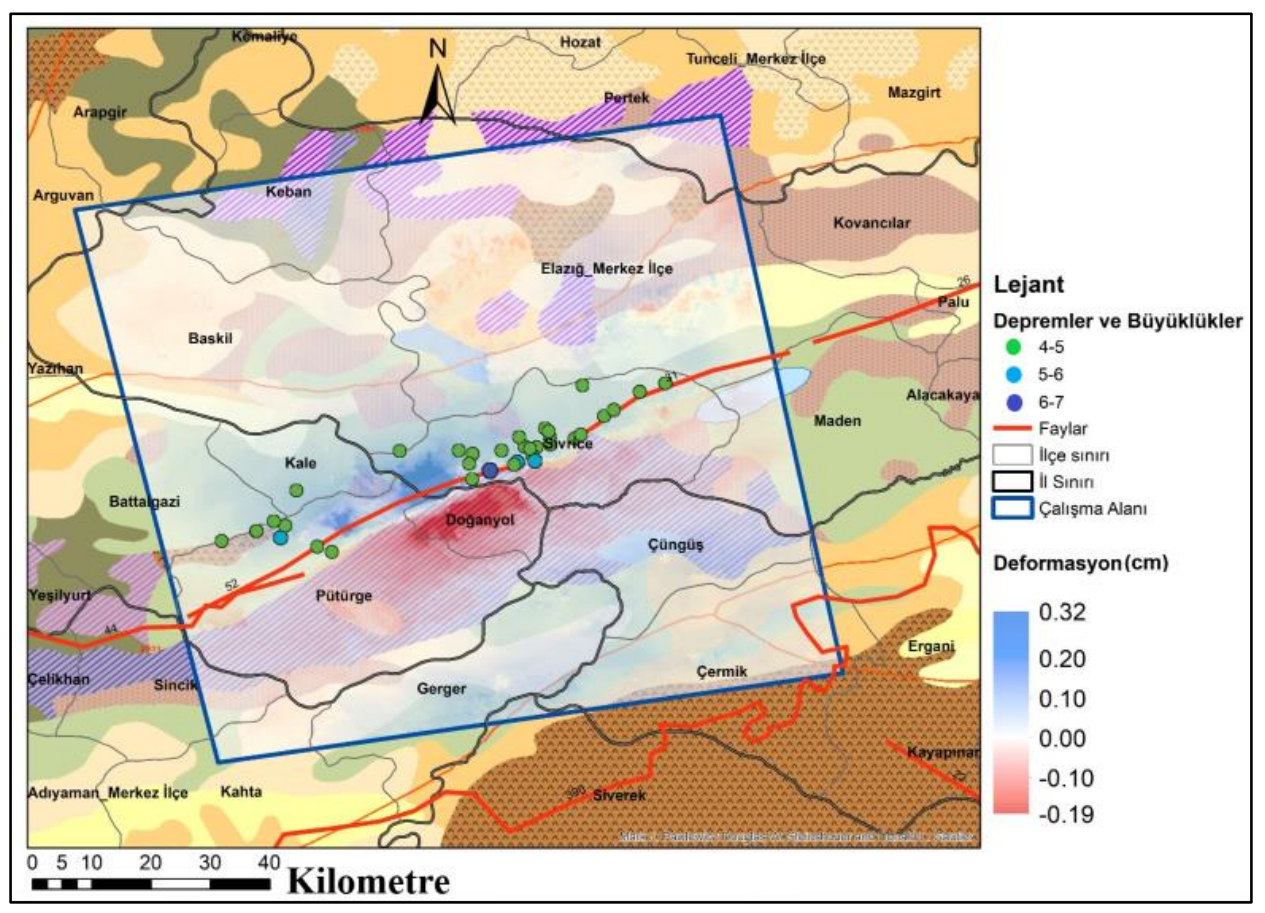

Şekil 10. Deprem kaynaklı yüzey çökme haritası

Çalışma alanındaki jeolojik birimlerin yüzey çökmesine etkisinin ortaya koyulması amaciyla SNAP yazılımından elde edilen veriler ArcGIS programındaki jeolojik haritalar ile çakıştırılmıştır. Şekil 10'daki haritadan maksimum çökme ve yükselme yapan jeolojik birimlerin Paleojenik ile Paleozoik ve prekambriyen metamorfik kayaçların olarak belirlenmiştir. Paleozoik ve prekambriyen metamorfik kayaç birimler daha fazla çökerken Paleojenik birimlerde yükselme görülmüştür. $\mathrm{Bu}$ sonuçlar yüzey çökmesinin jeolojik katmanlar ile bağlantılı olduğunu göstermektedir.

Bölgesel deformasyon modellerini tektonik hareketler, zeminin doğal sıkışması, yeraltı suyunun aşırı kullanımı vb. süreçler etkileyebilmektedir. Periyod aralığının kısa tutulması çalışma alanında gerçekleşen depremin deformasyondaki rolünü göstermiştir. Ayrıca çalışma alanının ani bir kentleşme veya aşırı yeraltı suyu tüketiminin gözlenmediği bir yer olması da bunu destekler niteliktedir. Bölgeye belirli sayıda kalıcı GPS istasyonunu kurulması, çökme hızı ve modelleri için bir doğrulama sağlayacak ve deformasyon mekanizmalarını açıklamaya yardıme olacaktır. Fayların konumu, yatay hidrolik iletkenlikteki ani süreksizlik nedeniyle arazi çökmesinin dağılımı üzerinde önemli etkiye sahiptir. Çalışma alanında, fay hareketinin yeraltı su kaynaklarına ve akifer sistemine etkisinin incelenmesi de gelecek araştırmalara değer katacaktır. Deprem sonrasında bölgedeki birçok araştırmacı tarafından saha gözlemleri yapılmıştır. Gökçeoğlu vd., (2020), Sivrice'de Hazar Gölü kıyısındaki alüvyon çökellerinde DAF zonu boyunca yüzey deformasyonlarının gözlemlendiğini belirtmiştir. $\mathrm{Bu}$ araştırmacılara göre, düşük kaliteli yapısal malzeme, inşaat ve işçiliğin yanı sıra, Çevrimtaş ve çevre köylerdeki yığma binalara ve altyapıya verilen ciddi hasarın bir diğer önemli nedeni, bölgede gözlenen yüzey kırılmasıdır. Arazi çökmesi fay hattının her iki tarafinda, kentsel altyapıları (yollar, demiryolları vb.) etkileyerek hasara neden olabilmektedir. Doğrultu atımlı fay mekanizmaları ile ortaya çıkan depremlerde faya yakın mesafelerde bulunan çok kat1ı yapıların, fayın kırılma yönünde konumlanmış olması durumunda fay kırığına dik doğrultuda sıra dışı bazı yıkıcı etkilere maruz kalabilecekleri bilinmektedir (Gillie vd., 2010). İleri direktivite etkisi denilen bu yıkıcı etki, ortaya çıkan deprem enerjisinin, ilgili kriterleri sağlayan, yapılara tek bir büyük yükleme çevrimi ile iletilmesi sonucu ortaya çıkmaktadır. Bu zararlı yıkıcı etkilerin ortaya çıkabilmesi için fay kırığının büyük oranda yapıların bulunduğu bölgeye doğru ilerlemesi gerekmektedir. Pütürge Segmenti'nde meydana gelen kırılmanın büyük ölçüde Güneybatı yönünde, Elazığ'ın tersi istikamette oluştuğu görülmektedir. Bu sebeple Elazığ Merkez bölgesi olası yıkıcı ileri direktivite etkilerine maruz kalmamış gibi görünmektedir (Şahin vd., 2020).

\section{Sonuç}

Sentetik açıklıklı radar (SAR) tabanlı uyduların geliştirilmesi, dünya çapında büyük jeolojik tehlikelere karşı önlemler türetilmesini sağlamıştır. 
İnterferometrik Geniş Alan (IW) modunun kullanılabilirliği ile Sentinel 1, interferometrik sentetik açıklıklı radar (InSAR) tekniklerini kullanarak yüzey çökmesini izleme yeteneğine sahiptir. Bu çalışma, Türkiye'nin Doğu Anadolu bölgesinde Sivrice(Elazığg)-Doğanyol(Malatya)Pütürge(Malatya) ilçelerini kapsayan alanda 24 Ocak 2020 tarihinde meydana gelen 6,8 büyüklügündeki depremle ilişkili yüzey çökmesinin haritalanmasında radar interferometri (DInSAR tekniği) kullanılarak SAR verilerinin yararlılı̆̆ııı göstermiştir. $\mathrm{Bu}$ depremi içeren 1 y1llık veriler, IW formatında 14 Haziran 2019 ve 08 Haziran 2020 tarihlerinde alınan S1B_IW_SLC_1SDV_20190614T151710_2019 0614T151737_016694_ 01F6B0_C963 ve S1B_IW_SLC_1SDV_20200608T151716_2020 0608T151743_021944_029A 54_8184 Sentinel-1 SAR verilerinin iki görüntüsüdür. SAR verileri, sismik olaydan sonra arazinin dikey olarak yer değiştirmesini değerlendirmek için kullanılmıştır. Analiz sonucunda sismik yönden en çok etkilenen alanların belirleniştir. Yüzey çökmesi daha çok Doğanyol(Malatya) kuzeyi ve Sivrice(Elazığ) batısı ile Doğanyol(Malatya) ve Pütürge(Malatya) bölgelerinin bazı bölgelerinde olmuştur. Hesaplanan dikey yer değiştirmenin $-19 \mathrm{~cm}$ 'den (Doğanyol ve Pütürge kuzeydoğusunda) $32 \mathrm{~cm}$ 'ye kadar (Doğanyol ve Pütürge kuzeyi ile Sivrice güneybatısında) olduğu belirlenmiştir.

Türkiye'nin deprem kuşağında yer alması ve sismik hareketlerin gün geçtikçe artması yıkıcı depremlerle karşılaşmasına neden olmaktadır. Tüm depremlerden sonra SAR verileri ile deprem kaynaklı zemin çökme analizinin yapılması önerilmektedir. Böylece çalışılan bölgede gelecekte benzer deprem meydana gelirse, olas1 çökme alanlarının önceden tahmin edilebilecektir. Analiz sonuçları deprem kaynaklı yüzey çökmesinden etkilenen ve etkilenebilecek yapıların tespiti için de önemli bir potansiyele sahiptir. SAR verilerinden elde edilen deprem hasarı bilgileri, hızlı deprem hasarı değerlendirmesi içinde kullanılabilecektir.

\section{Kaynaklar}

Abdikan, S., Imamoglu, M., Alasag, T., Toker, M., Kutoglu, S. H. and Sahin, S. (2019). Insar analysis of ayvacik 2017 (mw 5.3) earthquake swarm (canakkale, nw-Turkey). International Archives of the Photogrammetry, Remote Sensing and Spatial Information Sciences, 42(2/W13).
AFAD (T.C. İçişleri Bakanlığı Afet ve Acil Durum Yönetimi Başkanlığı Deprem Dairesi Başkanlığg1), (2020). https://deprem.afad.gov.tr.

AFAD (T.C. İçişleri Bakanlığı Afet ve Acil Durum Yönetimi Başkanlığı Deprem Dairesi Başkanlığı). (2020, Şubat). 24 Ocak 2020 Sivrice (Elazığ) depremi raporu. Erişim adresi, https://deprem.afad.gov.tr/download Document?id=1831

Ali, M., Shahzad, M. I., Nazeer, M., Mahmood, I. and Zia, I. (2019). Estimation of surface deformation due to Pasni earthquake using RADAR interferometry. Geocarto International, 1-16. https://doi.org/10.1080/10106049.2019.1661031

Amos, J. (2016, April 21). Sentinel maps North Korean nuclear blast aftermath. BBC. http://www.bbc.com/news/scienceenvironment-36103812.

Bayik, C. (2021). Deformation analysis of 2020 mw 5.7 Karliova, Turkey, earthquake using DInSAR method with different incidence angle SAR data. Arabian Journal of Geosciences, 14(4), 1-12. https://doi.org/10.1007/s12517-021-06670-X

Bell, J.W., Amelung, F. and Henry CD. (2012). InSAR analysis of the 2008 Reno-Mogul earthquake swarm: evidence for westward migration of Walker Lane style dextral faulting. Geophysical Research Letters, 39:1-5. https://doi.org/10.1029/2012GL052795

Gabriel, A. K., Goldstein, R. M. and Zebker, H. A. (1989). Mapping small elevation changes over large areas: Differential radar interferometry. Journal of Geophysical Research: Solid Earth, 94(B7),

9183-9191. https://doi.org/10.1029/JB094iB07p09183

Gillie, J. L., Rodriguez-Marek, A. and McDaniel, C. (2010). Strength reduction factors for near-fault forward-directivity ground motions. Engineering Structures, $\quad 32(1), \quad 273-285$. https://doi.org/10.1016/j.engstruct.2009.09.014

Gökçeoğlu, C., Şahmaran, M., Unutmaz, B., Aldemir, A., Koçkar, M.K., Sandıkkaya A. ve İçen A. (2020). 24 Ocak 2020 Elazı̆̆ Sivrice depremi $(\mathrm{mw}=6.8)$ ön inceleme raporu. Hacettepe Üniversitesi Mühendislik Fakültesi İnşaat Mühendisliği Bölümü, Ankara.

Hempton, M.R. (1985). Structure and deformation history of the Bitlis sture near Lake Hazar, southeastern Turkey. Geological Society of America Bulletin, 96, 233-243. https://doi.org/10.1130/00167606(1985)96\%3C233:SADHOT\%3E2.0.CO;2

Herece, E. ve Akay, E. (1992). Karlıva-Çelikhan arasinda Doğu Anadolu Fayı. Proceeding of the 
9th Petroleum Congress of Turkey. 17-21 February 1992, 361-372, Ankara, Turkey.

Hu, J., Li, Z. W., Ding, X. L., Zhu, J. J., Zhang, L. and Sun, Q. (2014). Resolving three-dimensional surface displacements from InSAR measurements: A review. Earth-Science Reviews, 133, 1-17. https://doi.org/10.1016/j.earscirev.2014.02.005

Kadirioğlu, F. T., Kartal, R. F., Kılıç, T., Kalafat, D., Duman, T. Y., Azak, T. E., Özalp, S. ve Emre, Ö. (2018). An improved earthquake catalogue $(\mathrm{M} \geq$ 4.0) for Turkey and its near vicinity (19002012). Bulletin of Earthquake Engineering, $16(8)$, 3317-3338. https://doi.org/10.1007/s10518-016-0064-8

Karslıoğlu, A., Alkayış, M. H., Kalkan, K. ve Onur, M. İ. (2020). Sentinel-1 uydusu ile Konya Karapınar ilçesi bölgesel çökme analizi. Disaster Science and Engineering, 6(2), 8-15.

Lakhote, A., Thakkar, M. G., Kandregula, R. S., Jani, C., Kothyari, G. C., Chauhan, G. and Bhandari, S. (2020). Estimation of active surface deformation in the eastern Kachchh region, western India: Application of multi-sensor DInSAR technique. Quaternary International. https://doi.org/10.1016/j.quaint.2020.07.010

Li, B., Li, Y., Jiang, W., Su, Z. and Shen, W. (2020). Conjugate ruptures and seismotectonic implications of the 2019 Mindanao earthquake sequence inferred from Sentinel-1 InSAR data. International Journal of Applied Earth Observation and Geoinformation, 90, 102127. https://doi.org/10.1016/j.jag.2020.102127

Massonnet D., Rossi M., Carmona C., Adragna F., Peltzer G., Feigl K. and Rabaute T. (1993). The displacement field of the Landers earthquake mapped by radar interferometry. Nature. 364(6433), https://doi.org/10.1038/364138a0

MTA (Maden Tetkik ve Arama Genel Müdürlüğü). (2020, Şubat 7). 24 Ocak 2020 sivrice (elazı ̆̆) depremi $(m w=6,8)$ saha gözlemleri ve değerlendirme raporu. Erişim adresi, https://www.mta.gov.tr/images/duyuru_ek/belge ler/609_07-02-2020_2b82a14b.pdf

Onur, M. İ., (2007). Dinamik etkiler altında zemin deformasyonunun incelenmesi. Yüksek Lisans Tezi, Anadolu Üniversitesi Fen Bilimleri Enstitüsü. Eskişehir.

Refice A., Bovenga F. and Nutricato R. (2004). Stepwise approach to InSAR processing of multitemporal datasets. In: Proc.of FRINGE 2003 Work ESA SP-550. http://earth.esa.int/workshops/fringe03/ proceedings/posters/83_refic.pdf.
Solaro, G., De Novellis, V., Castaldo, R., De Luca, C., Lanari, R., Manunta, M. and Casu, F. (2016). Coseismic fault model of Mw 8.32015 Illapel earthquake (Chile) retrieved from multi-orbit Sentinel1-A DInSAR measurements. Remote Sensing, 8(4), 323. https://doi.org/10.3390/rs8040323

Sowter, A., Amat, M. B. C., Cigna, F., Marsh, S., Athab, A. and Alshammari, L. (2016). Mexico City land subsidence in 2014-2015 with Sentinel-1 IW TOPS: Results using the Intermittent SBAS (ISBAS) technique. International journal of applied earth observation and geoinformation, 52 , https://doi.org/10.1016/j.jag.2016.06.015 $230-242$

Suresh, D. and Yarrakula, K. (2020). InSAR based deformation mapping of earthquake using Sentinel 1A imagery. Geocarto International, 35(5), 559-568. https://doi.org/10.1080/10106049.2018.1544289

Şahin H., Alyamaç K.E., Durucan A.R., Demirel B., Ulaş Açikgenç M., Bildik A.T., Durucan C., Demir T., Ulucan M., ve Demirbaş N. (2020). 24 Ocak 2020 Mw 6.8 Sivrice/Elazığ depremi Elazı ̆ bölgesi yapısal hasarlar inceleme ve analiz raporu, Yap1 ve Beton Uygulama ve Araştırma Merkezi, Fırat Üniversitesi, Rapor No:2020/D001, Elazı̆ğ, Türkiye.

Tatar, O., Sözbilir, H., Koçbulut, F., Bozkurt, E., Aksoy, E., Eski, S., Özmen, B., Alan, H. and Metin, Y. (2020). Surface deformations of 24 January 2020 Sivrice (Elazı̆̆ -Doğanyol (Malatya) earthquake $(\mathrm{Mw}=6.8)$ along the Pütürge segment of the East Anatolian Fault Zone and its comparison with Turkey's 100-year-surface ruptures. Mediterranean Geoscience Reviews, 1-26. https://doi.org/10.1007/s42990-020-00037-2

Thomas, A. (2020). Mapping of surface deformation associated with the 5.2 magnitude Stilfontein earthquake of 3 April 2017 using radar interferometry. The Egyptian Journal of Remote Sensing and Space Science. https://doi.org/10.1016/j.ejrs.2020.01.005

Thomas, A. (2020). Mapping of surface deformation and displacement associated with the 6.5 magnitude botswana earthquake of 3 april 2017 using dinsar analysis. Geomatics and Environmental Engineering, (14/4), 81-100. https://doi.org/10.7494/geom.2020.14.4.81

URL-1, (2020). Erişim adresi, https://sentinel.esa.int/web/sentinel/missions/sen tinel-1/instrument-payload.

Wang, H., Liu-Zeng, J., Ng, A. M., Ge, L., Javed, F., Long, F. and Shao, Z. (2017). Sentinel-1 observations of the 2016 Menyuan earthquake: A buried reverse event linked to the left-lateral 
Haiyuan fault. International Journal of Applied Earth Observation and Geoinformation, 61, 1421. https://doi.org/10.1016/j.jag.2017.04.011

Weston, J., Ferreira, A. M. and Funning, G. J. (2012). Systematic comparisons of earthquake source models determined using InSAR and seismic data. Tectonophysics, 532, 61-81. https://doi.org/10.1016/j.tecto.2012.02.001

$\mathrm{Xu}$, Guangyu, Xu, C. And Yangmao, W. (2018). Sentinel-1 observation of the 2017 Sangsefid earthquake, northeastern Iran: rupture of a blind reserve-slip fault near the Eastern Kopeh Dagh.
Tectonophysics 731-732, 131-138. https://doi. org/10.1016/j.tecto.2018.03.009. https://doi.org/10.1016/j.tecto.2004.04.008

Yazgan, E. (1984). Geodynamic evolution of the Eastern Taurus region. In Geology of the Taurus belt. International symposium (pp. 199-208).

Zebker, H. A. and Goldstein, R. M. (1986). Topographic mapping from interferometric synthetic aperture radar observations. Journal of Geophysical Research: Solid Earth, 91(B5), 4993-4999. https://doi.org/10.1029/JB091iB05p04993 